\title{
Development of the weather and climate service "CRITERION" for the touristic sector in e-SHAPE
}

We present the methodological development steps as well as first results of the e-Shape service CRITERION. The service is based on Copernicus ERA5 data for climatological information, the Copernicus C3S 50-member ensemble for the seasonal forecasting and on WRF local scale weather forecasts at $4 \times 4 \mathrm{~km}$ over Greece. Detailed information is provided at $\mathbf{2 0}$ UNESCO cultural heritage sites in Greece in the form of simple symbols and charts. The service has been developed by the Research Center for Atmospheric Physics and Climatology at the Academy of Athens and is operational since April 2021 at https://unesco-weather.gr/.

STAVROS SOLOMOS ${ }^{1}$, LIDA DIMITRIADOU ${ }^{1}$, JOHN KAPSOMENAKIS ${ }^{1}$, IOANNIS BINIETOGLOU ${ }^{2}$, PANAGIOTIS NASTOS ${ }^{1,3}$, CHRISTOS ZEREFOS $1,4,5,6$

\footnotetext{
${ }^{1}$ Research Centre for Atmospheric Physics and Climatology, Academy of Athens, Athens, Greece ${ }^{2}$ IAASARS, National Observatory of Athens, Athens, Greece

${ }^{3}$ Laboratory of Climatology and Atmospheric Environment, Department of Geology and Geoenvironment, National and Kapodistrian University of Athens, Athens, Greece

${ }^{4}$ Biomedical Research Foundation, Academy of Athens, Athens, Greece

${ }^{5}$ Navarino Environmental Observatory (N.E.O.), Messinia, Greece

${ }^{6}$ Mariolopoulos-Kanaginis Foundation for the Environmental Sciences, Athens, Greece
}

Introduction. Weather and climate information is necessary for decision-making for a range of tourism stakeholders. The decision to make a trip is greatly influenced by the physical and financial capabilities of the individual as well as by two important parameters: the individual's desires that are formed based on the climatic conditions prevailing in the place where she/he resides and the characteristics of the desired destination, such as the natural landscape, cultural features and climate that make it attractive. A typical example is the preference of the British for destinations abroad with milder climates (Amelung et al. 2007). Furthermore, the generic climatic conditions which would attract tourists may differ substantially from the actual prevailing conditions during their visit. Greece offers many options on which places to visit during a specific time schedule. Even the same site can offer a completely different experience when visited at different seasons. For these reasons we decided to develop a tailored weather and climate forecasting tool in the frame of e-Shape, focusing on 20 sites in Greece that have been declared by UNESCO as World Cultural Heritage sites (Fig. 1a).

Service Description and co-design. The service is named "CRITERION" since its purpose is to provide an additional climate-relevant criterion for stakeholders in the touristic sector as well as to individual visitors for planning their vacations and trips. It is developed by the Research Center for Atmospheric Physics and Climatology at the Academy of Athens and co-designed with the Institute of Greek tourism 
Please cite this article as DOI: https://doi.org/10.35614/ISSN-2341-6408-IK-2022-03-RL

confederation for the final format of the webpage and user options. Co-design was mainly focused towards three directions: i) Identify the locations for the pilot service; ii) Define the requested timescales for the forecasts and iii) Design the webpage. An iterative process was established with the end-user and through a series of discussions we came up with the idea to start from the emblematic UNESCO cultural heritage sites that are known worldwide and could provide a testbed for our developments. The requested forecasting window was three months for the seasonal forecast and four days for the short-range forecasts to facilitate both long-term and daily vacation planning. The final webpage structure was also co-designed to include a simple frontpage with minimal information and atmospheric symbols along with more advanced timeseries for the interested user.

The service is hosted at the Academy of Athens and is composed of three individual pillars as seen in Fig. 1b. First the local monthly climatology for each site is derived from the ERA5 dataset (Hersbach et al. 2020) for the period 2005-2019 including temperature, relative humidity, daily precipitation, and wind speed. These values are used to provide the prevailing climatological conditions at each site. This information is accompanied with a short description of each monument and can be used as a first step for deciding the visiting locations. The seasonal forecast is derived from the 51 ECMWF System 5 ensemble members (Stockdale et al. 2018) at single atmospheric levels, interpolated at each site. The ensemble forecasts are used without bias correction. The seasonal forecast is provided for three months ahead and is given along with the climatological values of each site, to provide a measure of possible deviation of certain atmospheric variables from their average values (Fig. 2a). Finally, the 4-day forecast is provided at each one of the CRITERION sites based on WRF-ARW v4.1.3 model (Skamarock et al. 2019) at $4 \times 4 \mathrm{~km}$ grid space over Greece. Such high resolution is required for the complex mountainous terrain of Greece in order to resolve local scale flows (e.g., downslopes, breezes, convective storms) and site-specific weather conditions (Solomos et al. 2021). The entire CRITERION process is fully automatic and is operational at the supercomputing cluster at the Academy of Athens. The development is mainly done in Bash shell scripting, Python scripting and Fortran environments.

Potential impact of the service. CRITERION provides a simple interface that can be easily adopted by tourism operators such as touristic agents, hotels, Airbnb apartments etc. The service is available at https://unesco-weather.gr/ and the webpage provides easy navigation and both simple and detailed information types for the interested visitor (Fig. 2a, b). The development modules can be easily expanded upon request to include also more sites in Greece. Application to other countries is also feasible and can be co-designed with potential end users to fulfil their specific needs.

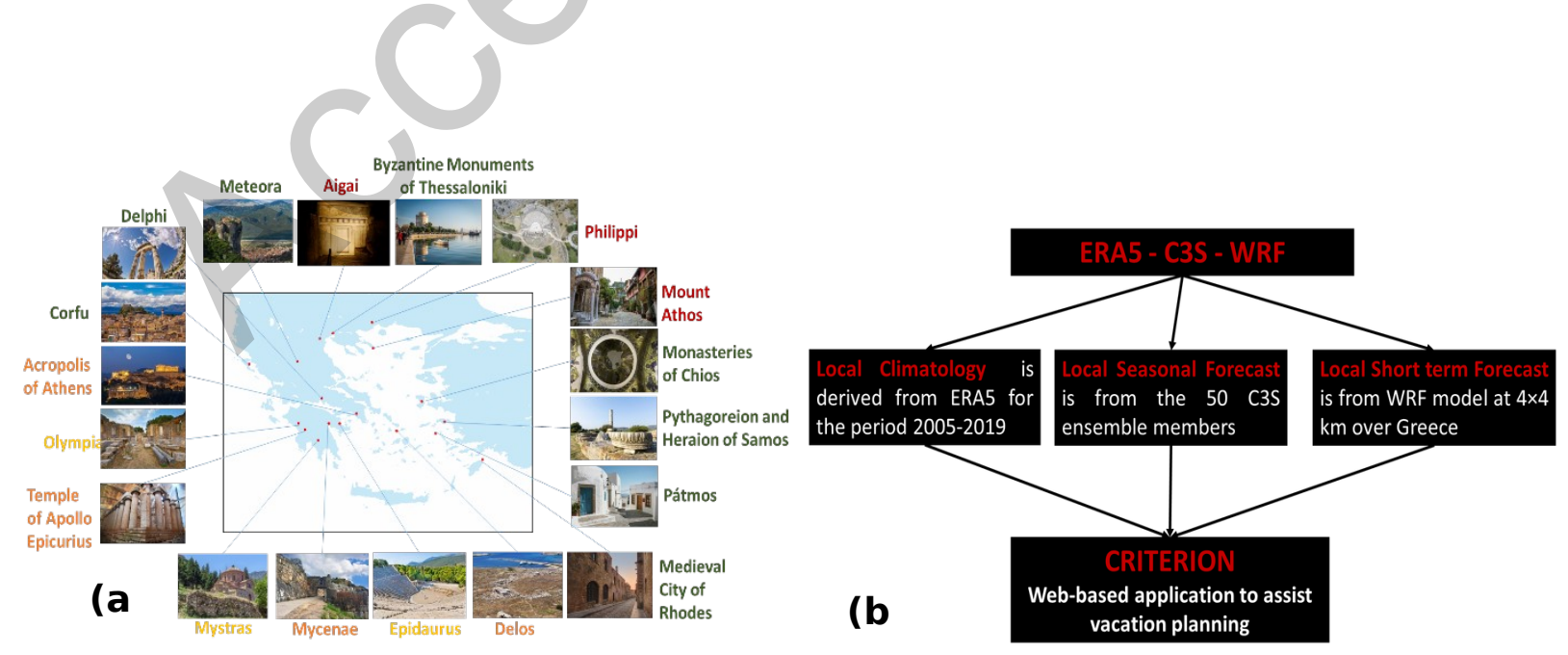

FIG 1: a) UNESCO cultural heritage sites in Greece b) CRITERION service methodological outline. 
Please cite this article as DOI: https://doi.org/10.35614/ISSN-2341-6408-IK-2022-03-RL
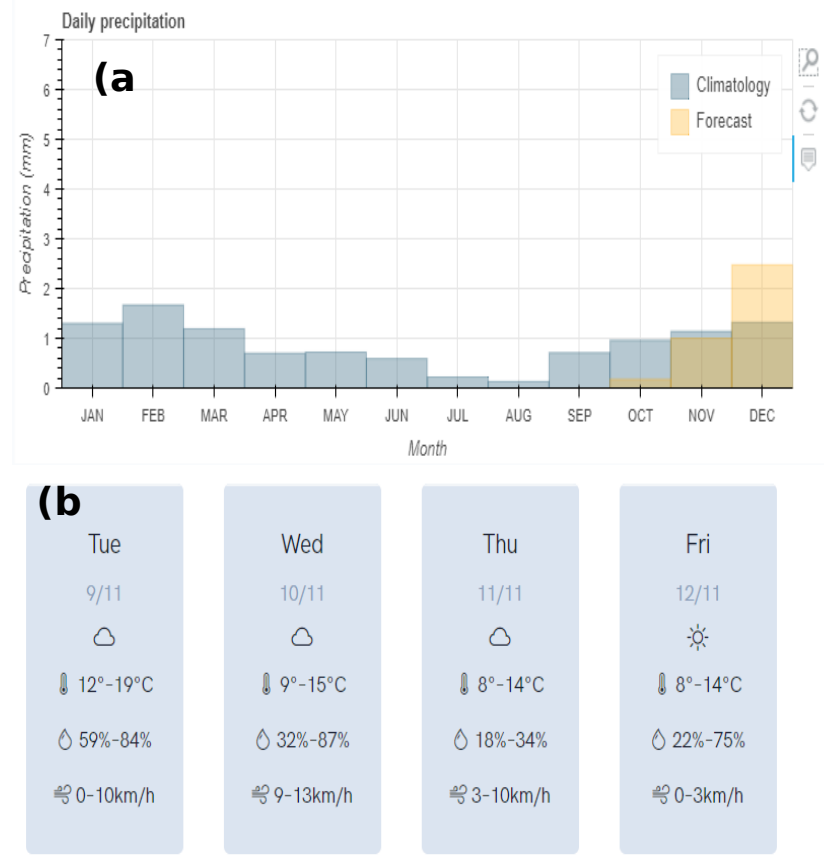

FIG 2: a) Example of local climatological values and seasonal forecast for the Acropolis of Athens. b) Example of local weather forecast for the Temple of Apollo Epicurius in Peloponnese.

\section{Acknowledgements}

The study contributes to e-shape project that is funded from the European Union's Horizon 2020 research and innovation programme under grant agreement 820852 .

\section{References}

Amelung B., et al., 2007: Implications of Global Climate Change for Tourism Flows and Seasonality. Journal of Travel Research, 45, 285-296, https://doi.org/10.1177\%2F0047287506295937.

Hersbach, H., et al. 2020: The ERA5 global reanalysis. Quart. J. Roy. Meteor. Soc., 146, 1999-2049, https://doi.org/10.1002/qj.3803.

Skamarock, W.C., et al., 2019: A Description of the Advanced Research WRF Model Version 4. NCAR Tech. Note NCAR/TN-475+STR, 145 pp., http://dx.doi.org/10.5065/1dfh-6p97.

Solomos, S., et al., 2021: A Modeling Study on the Downslope Wind of "Katevatos" in Greece and Implications for the Battle of Arachova in 1826. Atmosphere, 12, 993, https://doi.org/10.3390/atmos12080993.

Stockdale T., et al., 2018: ECMWF's new long-range forecasting system SEAS5. ECMWF Newsletter, No. 154

- Winter 2017/18, 15-20, http://dx.doi.org/10.21957/tsb6n1.

Keywords

e-Shape, CRITERION, UNESCO, Cultural Heritage, tourism, Seasonal Forecast, C3S, WRF, ERA5 